\title{
Women on the Academic Tenure Track: An Autoethnographic Inquiry
}

\author{
Laurie-Ann M. Hellsten, Stephanie L. Martin, Laureen J. McIntyre, Audrey L. Kinzel \\ University of Saskatchewan
}

\section{Introduction}

For novice faculty on the tenure-track achieving tenure means job security [1]. However, despite idealistic expectations [2], novice faculty report unbalanced lives and feelings of loneliness, isolation, and rivalry between colleagues [3]. Novice faculty also report becoming dissatisfied, overworked, stressed, and physically ill [4] as they attempt to meet the often unwieldy, vague, and increasing tenure and promotion requirements [5].

Men and women experience the tenure path differently [6]. Research also suggests that the structure of the academic workplace and the duration of the tenure-track (usually six years, although the time period differs by institution; [1]) are designed in ways that discriminate against women [7]. For fear of looking less committed or serious than male colleagues, female faculty members may even refuse to take advantage of parental leave policies such as maternity leave, halting the tenure clock during a maternity leave, and may even reconsider having a child or delay parenting [8]. Tenure-track appointments commonly require novice academics to perform adequately in three different arenas: research, teaching, and service. However, the weighting of the components does differ [9]. Gender disparities (e.g., salary, merit pay, etc.) resulting from inequities escalate when universities place more emphasis on research relative to teaching and service [10].

Kawalilak and Groen speak to the challenges and tribulations encountered by novice faculty pursuing the academic tenure track and suggest that sharing experiences can be "therapeutic, healing, and affirming” [11, p.6] for novice academics. Thus, the purpose of this study was to share the story of four female academics on the tenure track..

\section{Methodology}

We conducted an autoethnographic study of our experiences as three women who sought and earned tenure and promotion between 2003 and 2009, and one woman currently seeking tenure. Authoethnography is a form of narrative inquiry that legitimatizes the researcher's use of her own experience. The defining feature of autoethnography is that it requires the researcher write herself into the account of a phenomenon. Autoethnography emphasizes subjectivity and the written outcomes are as individual as its authors and may take a variety of different forms [12]. However, regardless of written form, the authoethnographic representation conveys the meaning attached to an experience. The goal of authoethnography is "...to tell a story that readers can enter and feel a part of” [12, p. 674].

Our goal was to closely examine our experience of being female academics in tenure-track positions. To generate data we individually and independently constructed, a detailed written account of our personal journey towards tenure. This written account served as an entry-point for a series of focused, digitally recorded conversations. As a collective, we reviewed each story and conversation and identified shared themes. Resiliency theory formed the framework for our discussion of our tenure track experience. Resiliency is defined as the ability to make positive adaptations in spite of serious threats or significant adversity to adaptation or development [13]. Resilience results from the operation of basic human adaptational systems including attachment, extended families, mastery motivation, and self-regulation [13]. Development in the face of adversity is robust when these basic systems are functioning. Conversely, when these systems are weakened, the risk for developing problems is much greater. Using the resiliency framework we asked ourselves, what factors in our lives have made it possible for us to navigate our tenure track journeys?

\section{Context}

Our faculty load is $40 \%$ teaching, $40 \%$ research, and $20 \%$ service. Tenure standards involve meeting established but vague standards for academic credentials, administration, teaching, knowledge of the discipline, and research and scholarly work. Faculty must successfully meet the standard in each of these categories. As a College of Education, teaching accountability is a focus but a wide-spread belief is that research productivity is the major factor in determining final tenure decisions. Furthermore, meeting the standard in research (i.e., being productive enough) has not been quantified in terms 
of a required number of publications or the number, type, and amount of research grants received. In response to the departure and retirement of four senior faculty members followed by two sabbatical leaves, a retirement, and a resignation, leadership roles were transferred from senior tenured faculty to junior tenure-track faculty. Our collective story reveals the shared challenges we experienced on the way to tenure. As our individual stories shared more commonalities than differences, we have chosen to amalgamate our individual stories into a composite story that highlights our shared experiences.

\section{Composite Story}

I am a woman, mother, daughter, friend, and I am on the academic tenure track. I was flattered by the opportunity of an academic job offer after many years of graduate studies and drawn to the flexibility and possibilities inherent in such work. I believed that an academic position would allow me to integrate my commitment to practice, research, and training. Although I had been advised by faculty of both genders not to have children until I received tenure, I looked forward to the birth of my second child and having a new workplace culture to navigate. Since my appointment, I've been learning the culture of academe, coping with a lack of support and feelings of isolation, trying to negotiate needs to live, work, and be well, and balancing commitments and making meaning.

\subsection{Learning the Culture}

To be awarded tenure means an academic has met the seemingly ever-increasing standards in teaching, research, and service. Although I received a teaching and administrative offload in the first year of my appointment to allow time to plan and teach new classes and attempt to start a research program, I've learned that each of these categories represents a full time job in itself! I've also discovered that it is difficult to be productive in any one of these areas without sacrificing the others. I wonder, what is the standard in each of these areas? What does it mean to be a productive academic.

I am not a teacher by training or profession and have a lot to learn in this area. Most of my learning about teaching has come through trial and error and dealing with failure, repeated failure it seems, has been painful. Negotiating students', colleagues', and program expectations has been a constant challenge. At every turn I am evaluated by peers, students, my department head, and review committees. Frequently (and sometimes) I'm left with contradictory, confusing, and unhelpful feedback. At my worst, I believed I was the absolute worst professor and that I would be terminated. At my best, I've been moved by students' aha moments, and believed that I could make a difference as an educator.

The category of research also presents challenges. Applying for funding means competing with more academics for less of the available funding pie. Applying for competitive grants also means taking time away from teaching, administrative, and service work. Even when I was successful in receiving two Tri-Council grants in one year, my productivity was not considered merit worthy. Furthermore, there is no secretarial, material, or other supports available through my department to support my research activity, which made the prospect of receiving further research funds highly unlikely. The thought of succeeding in a significant grant competition is also frightening; without support, time, and mental and emotional energy it does not seem wise or possible to take on more responsibility.

Contributing to service means sitting on committees. Although I knew we were short faculty, I realized the extent of our staffing problems when I became involved in too many committees, several of which were beyond my experience, interest, and expertise. Another part of the service area is contributing to my profession, which involves serving on non-university committees. I enjoy and find purpose in this work; my profession provides guidance, direction, and even support. Despite my commitments to community and profession, which profoundly inform my teaching, research, and service, these activities are not easily quantified. Therefore, they are not recognized as meritorious even though I needed to be licensed to be an academic

\subsection{Coping with a Lack of Support and Isolation}

Since my appointment, my department has experienced significant changes through resignations, retirements, and sabbatical leaves. I have had four different department heads in five years and the majority of my direct colleagues are on their own tenure journeys. Early on, there were no senior faculty members or formal mentors in our department to consult about workload expectations, procedure, or to whom to ask questions or to share fears. I sensed that everyone is just trying to survive in a time of increased pressure to produce and decreased resources and supports of all kinds.

My journey to tenure has been marked by a sense of isolation arising from the lack of regular mentorship, direction, guidance, and support. I have also been plagued with feelings of uncertainty, inadequacy, guilt, and frustration, along with fleeting moments of satisfaction. I enjoyed and appreciated occasional meetings with colleagues during the first year of my appointment, but my questions and need for support far outweighed the frequency of our 
conversations. Ultimately, I sought support from my former doctoral research supervisor (in a different province) who offered reassurance, provided perspective, and reminded me of the importance of support networks.

\subsection{Negotiating Life, Work, and Well Being}

I knew negotiating a balance between family, work, and well-being would be a challenge as I navigated the tenure-track. However, I didn't realize how stressed I was until I realized all of my off campus time was being spent in doctor's offices trying to treat my numerous medical maladies. In the first year of my appointment, I experienced health complications following the birth of my child and needed time to heal. On the spur of the moment, I chose to stop the tenure clock, but was not aware of the pros and cons of this option. The following year, I suffered the devastating loss of a family member, my main supporter, but did my best to work through my despair. Two years later, my father became very ill and, once again, my tenure and promotion package took a back seat to my care giving commitments.

I have struggled with feelings of inadequacy as I've tried to balance my roles as mother, wife, daughter, professional, and academic. Repeated health problems stemming in part from the stress of working at breakneck speed for prolonged periods of time with a spouse who tried to (but really couldn't) understand left me feeling discouraged and depleted. Early in my appointment, a senior colleague advised that everything I do ought to count toward tenure. With this in mind, I worked hard and long when able although switching from task to task as the day unfolds frequently results in an overall inattention and inability to focus at all. Guilt surfaces when I am with family and friends, when I can't fully link what I am doing to tenure. My basic self-care practices and sense of well-being have eroded. I realize I just cannot meet all academic demands and students' needs to my (and the tenure judges') satisfaction, let alone the needs of my spouse, children, and extended family members.

\subsection{Making Meaning}

Living an academic life is challenging and the toll on the road to tenure has been high. Although receiving tenure is touted as a pivotal event in an academic's life, the structure of academia suggests that I must not pause long to celebrate achieving this milestone or really any accomplishment; the next competition, submission, promotion is always just around the corner. Looking back, I realize that I am responsible for some of this toll. Rather than focusing on the negatives and pushing myself harder, I could have stopped to celebrate my successes and achievements, even the small ones. I could have talked with someone before I stopped the tenure clock when I needed time to heal from the birth of my child, taken bereavement leave upon the death of my loved one, and compassion leave when my father fell ill. When feeling pain in response to discouraging news, I could have taken time to reinvest in the aspects of my life that are nurturing and sustaining, reconsidered my values, and explored my options. When feeling pressured to take on more, I could have said no. Without question, turning to my peers who share this journey has been a saving grace as they've helped me to stay the course to tenure. Even though it's hard, taking care of myself along this journey is important because living with regret in exchange for tenure is not acceptable.

\section{Links to the Literature}

Our composite story and the conversations we held highlighted shared themes of: learning the culture; coping with a lack of support and isolation; negotiating life, work, and well-being; and making meaning of the tenure journey. Our experiences on the tenure journey are reflected in the literature.

We, as novice female faculty, are constantly overwhelmed by the conflicting demands inherent in our academic roles. As Wiebe and Fels stated "the intensity of academic life is bewildering” [9, p.16]. Academic life presents unique challenges because of the many jobs that are subsumed under the title of professor. "Although we are technically free to pursue research, teaching and service interests of our choosing, we are effectively limited by the scholarly activities that will 'look good' to the tenure review committees" [1, p. 45]. Despite being required to meet the standards in all categories including teaching, service, and research, we "know that publications in the top peer reviewed journals are our first hurdle" [9, p.16]. Wiebe and Fels further suggested, "As in any blood sport, academic competition leans toward reliance on quantity: of research grants received, conferences attended, and articles published" [9, p.18]. However, we often find ourselves burdened by mundane tasks such as grading assignments, reading and editing student research, attending meetings, and completing forms related to research (e.g., ethical approval, student time sheets, etc.) which although important (and maybe essential to the student, committee, or research project), are not quantifiable. Furthermore, research has shown that the lack of clear tenure criteria and the variability in tenure criteria are the single most stressful factors for new faculty [3]. What is the magic number that meets the publish or perish criteria? What does it mean to meet the minimum standard? We are not alone in our questions, Wiebe and Fels concurred: "How do we weight the value of production in the academy?” [9, 
p. 17]. Hirschkorn stated, "I apply for every grant funding opportunity that is even peripherally related to my work, commit to an overwhelming number of research/writing ventures, have joined several committees, and have volunteered to review for journals I have no time to read, all to hedge my bets against the perception that I may not have done enough" [1, p. 46]. For us at least, the tenure standards appear to be relative, shifting, and normreferenced. Although Hirschkorn questioned the fact that institutional "expectations may change from year to year" [1, p. 47], others have advocated something simpler: more clarity in terms of the tenure requirements [3], and consistency between and within departments [14].

A pervasive theme in our individual stories and across our discussions was our feelings of isolation and the questioning of the degree and quality of support we received throughout the tenure and promotion process. The tenure-track has been described as "lonely and circuitous, a maze of sorts" [11, p.6]. Unlike Hirschkorn, who found his Dean to be a "trusted mentor, advocate, and advisor" [1, p. 51], support from experienced colleagues may not always be available. When faced with a lack of quality support from experienced colleagues, tenure track faculty are often left to sort out performance expectations on their own, and self-doubt flourishes, "Even after a great Ph.D. experience and almost a decade of on the job experience, when I started my job I felt like a fraud.” We attempted to address our feelings of isolation and lack of support by forming our own support network. Research suggests that it is important to seek out other novice academics and connect "with one another through dialogue, in an attempt to combat deep feelings of isolation, confusion, and tentativeness that typically accompany the tenure-track experience" [11, p. 6].

Ironically, women are initially more attracted to tenure-track positions than men by the perception that the academy allows for a balanced lifestyle. Yet, females on the tenure track continually struggle to balance multiple their roles while attempting to progress in the academic world [15]. The challenge to achieve and maintain some sense of balance was expressed clearly by all four of the authors with one stating, "I find it so hard to reconcile what is expected of me in my role as faculty member in a new program and as a professional psychologist and parent.”

Parenting in the academy may be a professional liability for female academics [16]. Pregnancy prior to tenure has the potential to negatively impact women's careers [17]. The time demands of parenting may lead to a "parent and perish" situation for tenure track mothers [16, p. 1]. Although both male and female academics experience challenges balancing work and family, academic mothers have reported significantly more home and childcare responsibilities and less time for research than their male counterparts [16]. Accompanying the challenge of balancing parenting and academic demands are thoughts and feelings of self-doubt, "I feel as if I am never good enough - not a good enough teacher, researcher, mom, and not a good enough wife”. This doubt together with the balancing challenges results in significant emotional distress.

Working the long hours required of a demanding academic position can result in individual, marital, and family strain [18]. Being pulled in multiple directions, one of the authors stated, "I was making myself sick trying to stay ahead of deadlines and meet my job expectations. I had no balance everything was about work.” Clearly tenure holds more weight than all other obligations together.

According to Digiorgio [14, p.31], "the attainment of tenure is not much different from any other hierarchy of a profession. The symbolic status of tenure is won after a battle with one's self.” But we question, at what cost is tenure achieved? For example, "You know you're in trouble when you start wondering whether coaching your daughter's soccer team would be 'good for your CV" [9, p.17]. We found that working to balance our roles as female academics required an intensity of work that greatly affected our health and well-being. We must advocate for a change so that we no longer hope to achieve work-family balance only after tenure [19].

In order to foster understanding and change, we hope others consider our story an agent for action and change. Female academics are in ideal positions to provide each other with support and be role models for each other regardless of rank. This is especially true in situations where there may be a mentorship void [20]. We want to now strive to not only listen to but also reach out and offer support, guidance, and mentorship to female tenure-track faculty as:

Pre-tenure faculty is the lifeblood of our disciplines and of the academy. It behoves us to ask them: What is it that brought you here?... What do you hope to have accomplished and how can we help you get there?... Listening is not enough. We must be influenced by what we hear and find ways within our own contexts to respond effectively. [19, p. 80]

There is "power and potential" when female academics on the tenure-track connect with one another through sharing their stories [11, p. 5]. It seems that we, as our women academics are aware/know what to do and how to do it and realize it can be achieved.

\section{Conclusion}

After three of our group received tenure, we have begun to implement strategies to improve the balance 
between our personal and professional lives, and have encouraged our untenured group member to do the same. Our self-created peer support group has allowed us to openly communicate our hopes, fears, and concerns during our respective tenure journeys. From a resiliency perspective, assertiveness, communication and/or negotiation skills (i.e., internal assets), mentorship, faculty development, and faculty peer groups (e.g., external resources) can assist female academics to experience success and advancement in their careers. Our resiliency strategy has been to make ourselves accountable, to ourselves and each other, for the healthy and unhealthy choices we make. We are supporting each other to make the often difficult, yet essential choice, to take care of ourselves. We are striving to become better role models and mentors to junior female academics who are negotiating their own journeys to tenure.

\section{References}

[1] M. Hirschkorn, "How vulnerable am I? An experiential discussion of tenure rhetoric for new faculty". Journal of Educational Thought, 44(1), 2010, pp. 41-54.

[2] R. Rice, M. Sorcinelli, M. and K. Austin, K Heeding New Voices: Academic Careers for a New Generation. American Association for Higher Education, Washington, DC, 2000.

[3] H. C. Greene, K. A. O' Connor, A. J. Good, C. C. , Ledford, B.D. Peel, and G. Zhang, "Building a support system toward tenure: Challenges and needs of tenuretrack faculty in colleges of education”. Mentoring \& Tutoring: Partnership in Learning, 16(4), 2008, pp. 429447.

[4] N. R. Hill, "The challenges experienced by untenured faculty members in counsellor education: A wellness perspective". Counsellor Education and Supervision, 44, 2004, pp. 135-146.

[5] J. Schuster and M. Finklestein, The American Faculty: The Restructuring of Academic Work and Careers. Johns Hopkins University Press, Baltimore, MD, 2006.

[6] A. L., Wright, L. A., Schhwindt, T. L., Bassford, V. F. Reyna, C. M. Shisslak, P. A. St. Germaine, and K. L. Reed, "Gender differences in academic advancement: Patterns, causes, and potential solutions in one U.S. College of Medicine”. Academic Medicine, 78(5), 2003, pp. 500-508.

[7] D. F. Halpern, "Nurturing careers in psychology: Combining work and family". Educational Psychological Review, 20, 2008, pp. 26-31.

[8] K. Ward, K. and L. Wolf-Wendel, "Fear factor: How safe is it to make time for your family?” Academe, 90(6), 2004, pp. 28-31.
[9] S. Weibe and L. Fels, "Thinking around tenure: Ducking under the finish line”. Journal of Educational Thought, 44(1), 2010, pp. 11-26.

[10] M. A. Mason and M. Goulden, M., "Do babies matter? The effect of family formation on the lifelong careers of academic men and women”. Academe, 88(6), 2002, pp. 21-27.

[11] C. Kawalilak, and J. Groen, "Perspectives - The road to tenure”. Journal of Educational Thought, 44(1), 2010, pp. 5-9.

[12] C. Ellis, C, "Heartful autoethnography”. Qualitative Health Researcher, 9(5), 1999, pp. 653-667.

[13] A. S. Masten, “Ordinary magic: Resilience processes in development”. American Psychologist, 56, 2001, pp. 227-238.

[14] C. Digiorgio, "Capital, power, and habitus: How does Bourdieu speak to the tenure process in Universities?" Journal of Educational Thought, 44(1), 2010, pp. 27-40.

[15] S. Riger, J. Stokes, S. Raja, \& M. Sullivan, "Measuring perceptions of the work environment for female faculty". Review of Higher Education, 21(1), 1998, pp. 63-78.

[16] C. Yoest and Se. E. Rhoads, What if...Parenthood wasn't a professional peril on the tenure track? Must academics parent and perish? Paper prepared for the Annual Meeting of the American Association of Public Policy Analysis and Management, Dallas, Texas, November 2002.

[17] H. Etzkowitz, C. Kemelgor, M. Neuschatz, and B. Uzzi, "Barriers to women in academic science and engineering”. In Willie Pearson Jr. \& Irwin Fechter (Eds.), Who Will Do Science? Educating the Next Generation (pp. 43-67). Johns Hopkins Press, Baltimore, 1994.

[18] M. Martha, P. Shelley, and L. Lynn, "Taking its toll: The influences of paid and unpaid work on women's wellbeing”. Feminist Economics, 11(1), 2005, pp. 63-94.

[19] K. M. Hibbert, R. Stooke, K., Pollock, I., Namukasa, F. Faez, and J. O’Sullivan, "The "ten-year road”: Joys and challenges on the road to tenure". Journal of Educational Thought, 44(1), 2010, 69-84.

[20] L. M. Hellsten, S. Martin, and L. J. McIntyre, "Navigating the potholes and speed bumps: Three female perspectives on tenure and promotion". Journal of Educational Thought, 44(1), 2010, pp. 99-116. 